\title{
METODOLOGIA DE ENSINO DA DISCIPLINA ESTATÍSTICA PARA GESTORES: ANÁLISE DO ENGAJAMENTO DOS ESTUDANTES AOS INSTRUMENTOS AVALIATIVOS NO AMBIENTE VIRTUAL DE APRENDIZAGEM BLACKBOARD
}

SÃO PAULO/SP MAIO/2018

\author{
Cláudia Leite Machado - Laureate - claudia.machado@eadlaureate.com.br \\ Clovis Mendes de Vasconcelos Sobrinho - Laureate - clovis.sobrinho@eadlaureate.com.br \\ Cristiane Coelho Teles - Laureate - cristiane.teles@eadlaureate.com.br \\ Danilo Santiago Gomes Valentim - Laureate - dsvalentim@eadlaureate.com.br \\ Marcia Aparecida dos Santos - Laureate - marsantos@eadlaureate.com.br
}

Tipo: Investigação Científica (IC)

Natureza: Relatório Final de Pesquisa

Categoria: Métodos e Tecnologias

Setor Educacional: EDUCAÇÃO SUPERIOR

\begin{abstract}
RESUMO
O propósito central deste trabalho foi analisar o engajamento dos estudantes aos instrumentos avaliativos por meio da aplicação de metodologia de ensino da disciplina Estatística para Gestores no Ambiente Virtual de Aprendizagem Blackboard. A natureza desta pesquisa foi a revisão bibliográfica aprofundada e qualitativa de observação, decorrente de pesquisas bibliográficas e analise dos indicadores de execução das atividades na plataforma. O estudo foi realizado com os estudantes de graduação, bacharelado na modalidade EaD na disciplina Estatística para Gestores, sendo a base de estudo a disciplina em pauta classificada como pool, ou seja, que se encontra em diversos cursos da área de Gestão e Negócios, pela representatividade de estudantes e interdisciplinaridade inerente. $O$ resultado obtido foi constatar o engajamento e consequente ensino-aprendizagem com a metodologia de ensino utilizada pelo docente responsável pela disciplina. Percebe-se que os estudantes se sentem subsidiados na construção de seu conhecimento, em um dos temas tradicionalmente sinalizados como mais desafiadores, como a Estatística, desta forma, estimulando o enriquecimento do aprendizado e sua contínua construção.
\end{abstract}

Palavras-chave: Metodologia de Ensino, Educação a Distância, ensino- aprendizagem, engajamento 
Introdução

Com o decorrer dos anos foi possível observar as diversas transformações da educação, como por exemplo, a consolidação da educação a distância no Brasil, que se constitui contemporaneamente com a quebra de paradigmas, bem como alinhamento aos avanços tecnológicos existentes. Entretanto, a essência do "aprender a aprender" em sintonia à mediação de um corpo docente e tutorial alicerçados no compromisso da transmissão de informação com riqueza de detalhes, bem como propósitos metodológicos contínuos que estimulam a participação e engajamento se constituem como o eixo do segmento em pauta, uma vez que prioriza e foca na essência do exposto, ou seja, o estudante.

Conforme Vygotsky(1987), observa-se que o desenvolvimento do pensamento flui do social para o individual e portanto a construção da maior parte da aprendizagem se dá a partir das relações sociais, da conversa, do diálogo, das atividades em grupo, desta forma, se consolidando o efetivo papel das metodologias de ensino-aprendizagem utilizadas.

Com o decorrer deste artigo que se encontra estruturado em 05 capítulos, observar-se-á este primeiro intitulado como introdução, o segundo com a apresentação do problema de pesquisa e objetivo partindo da seguinte questão orientadora: $O$ ensinoaprendizagem da disciplina Estatística para Gestores fomenta, em decorrência da metodologia de ensino utilizada pelo docente responsável, o engajamento aos instrumentos avaliativos inerentes e propostos? O terceiro arcabouço teórico que fundamenta o artigo por meio de citações e referenciais teóricos, no quarto a apresentação dos procedimentos metodológicos e finalizando com o quinto capítulo conclusões e recomendações.

Problema de pesquisa e objetivo

O problema que alicerça esse trabalho consiste em entender se: $O$ ensinoaprendizagem da disciplina Estatística para Gestores fomenta, em decorrência da metodologia de ensino utilizada pelo docente responsável, o engajamento aos instrumentos avaliativos inerentes e propostos? Onde o objetivo geral do trabalho concentrou-se em identificar o engajamento e consequente ensino-aprendizagem com a metodologia de ensino utilizada pelo docente responsável na disciplina em pauta.

Arcabouço Teórico 
Este capítulo, destinado à apresentação e reflexão acerca das Metodologias de ensino, não tem o objetivo de oferecer receitas, tão pouco a pretensão de rotular professores como satisfatórios ou insatisfatórios na sua prática docente. Sabe-se que na educação, como na vida, não existem receitas finitas, muito menos fórmulas mágicas para o êxito. Satisfatoriamente, segundo Gandin, citado por Foresti(2007), " para quem sabe aonde vai, os caminhos são vários".

Segundo Foresti(2007) a conceituação de metodologia, aplicada à proposta pedagógica, possuem um sentido amplo, que não se restringe à forma de desenvolver uma aula ou aplicar a atividade prática inerente. Direciona-se além de uma ação mecanicista, com uma definição clara dos fins que se pretende alcançar, "articulados às nossas concepções de educação de homem e sociedade".

Desta forma, a metodologia é parte imprescindível do processo educativo e deve levar em consideração um conjunto de fatores: as atividades propostas, a bibliografia, o sistema de avaliação, os métodos ou técnicas eleitos, o relacionamento com os estudantes, a relação entre a disciplina e o curso, bem como o propósito pedagógico, social e institucional da IES (Instituição de Ensino Superior).

Ainda, conforme Foresti(2007), "a nossa metodologia, portanto, está relacionada com a nossa concepção pedagógica, com a visão de educação, do homem e da sociedade, construída criticamente a partir da reflexão que fazemos sobre o trabalho que realizamos. Ou seja, é um processo de construção pessoal, ao longo de nossa formação e das experiências de nossa vida profissional".

Preocupações acerca de um ensino eficiente, construído com práticas e métodos eficientes e eficazes, não são recentes. Cabe ponderar sobre essa questão dentro de um perspectiva histórica ao ler Jan Comênio ( 1592-1670), reconhecido como o " pai da didática”, e seus conceitos extremamente contemporâneos, sinalizados por Doll e Da Rosa (2004), quando observam que a aprendizagem deve começar, conforme Comênio, a partir dos sentidos, da percepção, da experiência do estudante, e não apenas de teorias abstratas. Dentro desse sentido, Comênio, questiona as instituições de ensino, quanto a formação de estudantes que repetem nomes e conceitos sem efetivamente sinalizarem a compreensão e interiorização do que verbalizam. Contraposto a isso, propõe que os estudantes realizem experiências, aprendendo a partir de suas observações, sem repetições, mas alicerçados na pesquisa como principio pedagógico.

Fundamentações acerca de aprendizagem merecem reflexões, uma vez que, o que leva uma pessoa a aprender, bem como a forma de ensinar a aprender são práticas 
indissociáveis. Entender que o que leva ao aprendizado decorre, antes de como ensinar, como compreender o que mobiliza a busca, gera estímulo, consequentemente, interpretação, interiorização e transformação das informações observadas, que uma vez adicionadas ao repertório pré-existente constituirão conhecimento efetivo.

A premissa leva a percepção do aprendizado como contínuo e progressivo, cabendo ao docente, dentro desta perspectiva, o planejamento de sua base metodológica, com estratégicas e procedimentos dinâmicos, em sintonia com as expectativas dos estudantes, desafiando-os e estimulando-os para uma atuação ativa, independente e gestora da consolidação de seus resultados alcançados.

Adicionalmente ao posicionamento do docente, cabe complementar acerca de que seu papel deve concentrar-se como um orientador e mediador pedagógico, proporcionando as ferramentas e ambientes de ensino-aprendizagem necessários para o devido desenvolvimento das capacidades, de analise, síntese, comparação e avaliação por parte do corpo discente.

Segundo Perrenoud(2000), pertinente e relevante compreender que docentes e formadores não representam o mesmo oficio, mas que convergem-se uma vez que ambos atuam no sentido de entender a comunidade de estudantes como um espaço de manifestações individuais, bem como coletivas. Visualizando o grupo como um sistema em rede, onde as trocas acontecem horizontalmente, e portanto demandando o posicionar-se como um mediador e agente mobilizador de estruturas, recursos e negociações internas e externas.

Conforme Ivani Fazenda, citada por Klein (2006), existe uma indiscriminada proliferação de propostas intuitivas e projetos educacionais que usam o termo "interdisciplinar", geralmente de forma aleatória, sem clareza, tão pouco regras. Ainda, segundo a autora, mais que o desenvolvimento ou metodologia interdisciplinar, o que realmente constituirá diferencial competitivo e valor agregado é a postura interdisciplinar do professor, agente de transformação educacional, cultural e social.

Percebe-se que a construção do conhecimento baseia-se em uma perspectiva de que o ser humano é ativo e envolvido em relações, desta forma, não podendo ser o conhecimento transferido, mas sim desenvolvido por ele na sua relação com os outros e com o mundo.

Procedimentos Metodológicos 
Sinalizam-se a seguir os procedimentos metodológicos que norteiam a proposição da pesquisa, adicionalmente aos procedimentos de pesquisa utilizados na consolidação do artigo em pauta.

O trabalho concentrou-se em identificar o engajamento e consequente ensinoaprendizagem por meio da metodologia de ensino utilizada pelo docente responsável na disciplina Estatística para Gestores de uma IES(Instituição de Ensino Superior).

Utilizou-se como metodologia de pesquisa adotada a revisão bibliográfica aprofundada e qualitativa de observação, relativa ao tema inicialmente proposto. Cabe ponderar que, a pesquisa bibliográfica desenvolve-se com material já constituído, alicerçada em artigos publicados nacional e internacionalmente, bem como livros publicados por autores engajados e que desenvolvam contínua pesquisa acerca dos temas. Em paralelo, a qualitativa de observação posiciona-se no sentido de possibilitar uma maior compreensão do objeto de estudo, esclarecendo-o ou constituindo hipóteses adicionais e complementares.

O estudo foi realizado com os estudantes de graduação, bacharelado na modalidade EaD na disciplina Estatística para Gestores, com vigência previamente firmada conforme regimento no período de 09/10/17 à 22/12/2017, e sendo a base de estudo a disciplina em pauta classificada como pool, ou seja, que se encontra em diversos cursos da área de Gestão e Negócios, pela representatividade de estudantes e interdisciplinaridade inerente. A disciplina foi ministrada utilizando o Ambiente Virtual de Aprendizagem, AVA Blackboard.

Dividida em quatro unidades, cada uma com seus respectivos instrumentos avaliativos, que constituem o consolidado de atividades, intitulado com Atividades N1, objeto de estudo desta pesquisa. Onde o cronograma de execução das atividades demandava a execução da Atividade 1 (Proposta Pedagógica com 3 questões dissertativas delimitadas em resposta principal, réplica e tréplica) com vencimento para a data de 08/11/2017, Atividade 2(Proposta Pedagógica com 10 questões objetivas) com vencimento para a data de 30/11/2017, Atividade 3(Proposta Pedagógica com 1 questão dissertativa) com vencimento para a data de 20/11/2017 e Atividade 4(Proposta Pedagógica com 10 questões objetivas) com vencimento para a data de 30/11/2017.

Participaram da pesquisa 376 estudantes inscritos e com frequência de acesso ao Ambiente Virtual de Aprendizagem no período de 09/10/17 à 08/11/2017, recorte temporal este, determinado para a devida realização de consolidação de resultados, tabulação e analise. 
Observa-se que, à título de atendimento aos requisitos estabelecidos, no que tange a vigência das atividades, da amostra delimitada,

$100 \%$ dos estudantes observados cumpriram a entrega da Atividade 1 até a data de encerramento, sem atrasos, atividade essa, previamente firmada conforme regimento da disciplina com encerramento para a data de 08/11/2017;

$62 \%$ dos estudantes observados anteciparam em 22 dias a entrega da Atividade 2 previamente firmada com encerramento para a data de 30/11/2017;

49\% dos estudantes observados anteciparam em 12 dias a entrega da Atividade 3 previamente firmada com encerramento para a data de 20/11/2017 e

$31 \%$ dos estudantes observados anteciparam em 22 dias a entrega da Atividade 4 previamente firmada com encerramento para a data 30/11/2017.

Os dados coletados decorrem de observação de base de dados disponível no Centro de Notas Inteiro do Ambiente Virtual de Aprendizagem - AVA Blackboard, adicionalmente à observação de interações e mediações do canal de atendimento Fale com o Professor/Tutor para esclarecimentos de dúvidas e posterior desenvolvimento das atividades propostas.

Figura 1 - Gráfico elucidativo apresentado em quantidades das Atividades Avaliativas em pauta.

\section{Atividades Avaliativas até a data de 08/11/17}

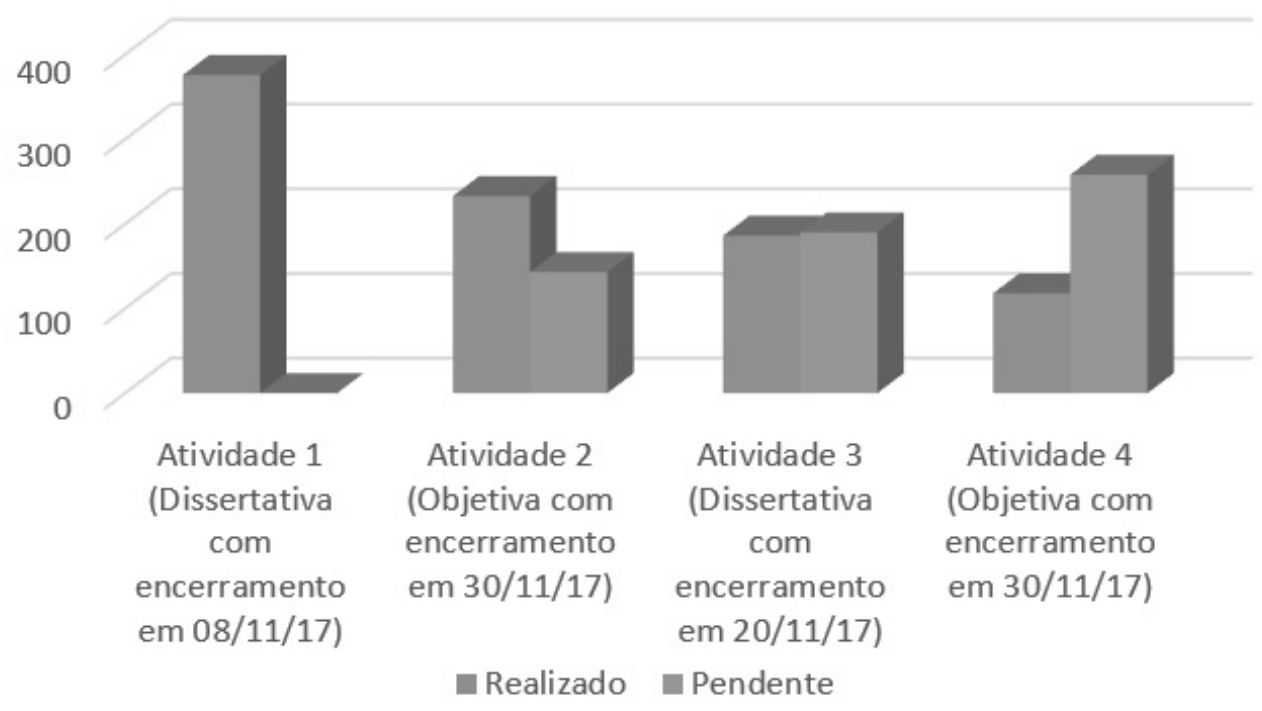


Figura 2 - Gráfico elucidativo apresentado em percentuais das Atividades Avaliativas em pauta.

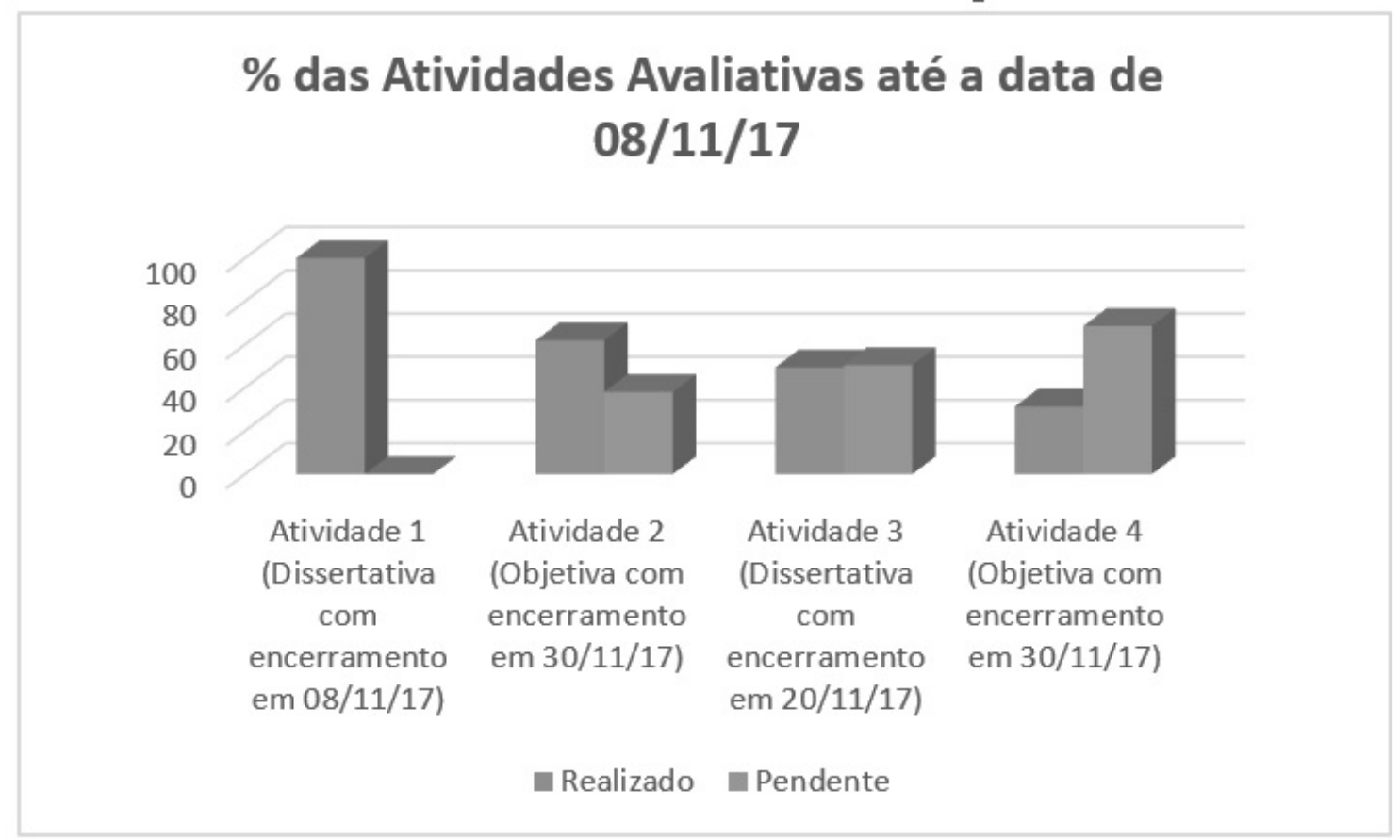

Conforme regimento inerente à disciplina. previamente estabelecido no início das atividades propostas, docente e tutor postaram avisos acerca do inicio e vigência das mesmas, avisos estes automaticamente direcionados com cópia para o mailing de emails disponíveis no Ambiente Virtual de Aprendizagem e que se posicionam como um dos canais de comunicação com a comunidade de estudantes inscritos na plataforma. Tal postura objetiva estimular a participação, como parte do processo de interação e mediação. Como embasamento teórico, em sintonia, foi possível observar o Material Referencial, composto por E-book, Vídeo, Game, Quiz, PageFlip e Biblioteca Pearson), bem como Materiais Complementares, vídeo no Youtube, adicionalmente à artigos com sinergia ás bases tecnológicas da disciplina.

Percebe-se significativa e satisfatória aderência aos instrumentos inicialmente propostos, bem como o devido atendimento aos regimentos administrativos e pedagógicos estabelecidos com 0 intuito de subsidiar o fomento de ensinoaprendizagem. Cabe salientar, a proposta pedagógica de disponibilização de atividades avaliativas para cada uma das quatro unidades de fundamentações disponibilizadas em que a disciplina se encontra constituída.

Conclusões e Recomendações

Pondera-se, conforme salientado anteriormente, que este artigo não possui a pretensão 
de estabelecer métodos, processos didáticos ou fórmulas prontas para mediação e interação com a comunidade de estudantes. Objetiva, sim, sinalizar questões práticas e fundamentadas com a aplicação do docente no seu caráter mais amplo, lato, ou seja, como um agente de fomento de estímulos, reflexão, bem como definição de propostas e pretensões pedagógicas não somente para o seu componente curricular ou disciplina, mas do curso, percurso formativo, desenvolvimento profissional, cultural e social de seu público-alvo, ou seja o estudante.

A metodologia utilizada contribuiu para o debate acerca dos procedimentos estabelecidos, bem como resultados apresentados, adicionalmente à fundamentação para geração de estímulos e participação por parte do estudante e docente, em sintonia, frente às práticas pedagógicas.

Cabe salientar que não se trata de um processo finito, acabado, mas que demanda gestão, observação, perícia, auditoria e melhoria continua para que permaneça atrativo e pertinente.

Em vias de encerramento, lembrar que o tempo dedicado ao estudante é muito escasso, se comparado à dimensão de habilidades e competências objetivadas, mas que a postura com atitudes que se posicionem como referência, e despertem a curiosidade e motivação sinalizam-se como um dos caminhos.

Figura 3 - Mensagem registrada em um dos canais de atendimento e de relacionamento da comunidade de estudantes com o corpo docente e tutorial.

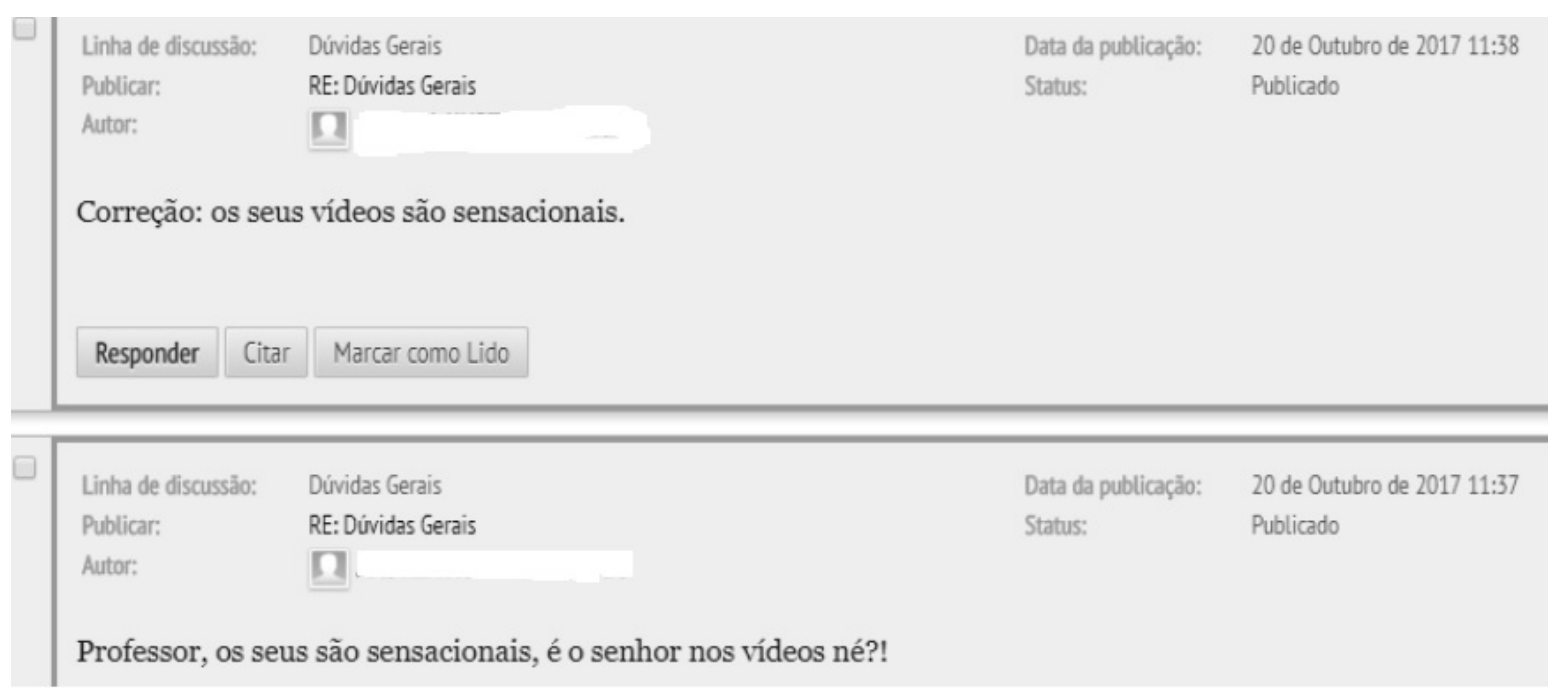

Por fim, tem-se acima o compartilhamento de uma das muitas percepções observadas em um dos canais de atendimento disponibilizados, como fonte de inspiração para a continuidade de compromisso com o oficio em pauta, ou seja, o ser docente e não 
apenas o estar docente.

\section{REFERÊNCIAS BIBLIOGRÁFICAS}

BATTES, Tony. Educar na era digital: design, ensino e aprendizagem. São Paulo, SP: Artesanato Educacional, 2016.

DOLL, Johannes e DA ROSA, Russsel Teresinha Dutra. Metodologia de ensino em foco - Práticas e reflexões. Porto Alegre: Editora da UFRGS,2004.

FAZENDA, Ivani(org). Didática e interdisciplinaridade. Campinas, SP: Papirus, 1998.11 edição, 2006. Coleção Práxis.

FORESTI, Miriam Celi P.Porto. Sobre prática pedagógica, planejamento e metodologia de ensino: a articulação necessária. Disponível em: acesso em 18/05/2018.

FREIRE, Paulo. Pedagogia da autonomia: saberes necessários à prática educativa. 33 edição. São Paulo, SP: Paz e Terra, 2006.

KLEIN, Julie Thompson. Ensino interdisciplinar: didática e teoria. Em: Didática e Interdisciplinaridade, de FAZENDA, Ivani(org)p.109 a 132.

PERRENOUD, Philippe. Pedagogia diferenciada - Das intenções à ação. Porto Alegre: Artes médicas Sul, 2000.

VYGOTSKY, L.S. A formação social da mente. São Paulo: Martins Fontes, 1984. 